\title{
Torka Motor Induksi pada Mesin CNC di PT. Dirgantara Indonesia menggunakan Software PSIM
}

\author{
SENI NURJANAH, NASRUN HARIYANTO, SABAT ANWARI
}

Program Studi Teknik Elektro, Institut Teknologi Nasional Bandung, Indonesia

Email : senurjanahh@gmail.com

Received 19 April 2021 | Revised 11 Mei 2021 | Accepted 24 Juni 2021

\begin{abstract}
ABSTRAK
Mesin CNC digunakan untuk membuat kerangka pesawat terbang, motor induksi sebagai tenaga penggerak diatur kecepatan putarnya untuk menghasilkan torka sesuai kebutuhan dikendalikan oleh VSD. Pengendalian VSD pada mesin CNC menggunakan software PSIM untuk mengetahui karakteristik mesin CNC dengan tegangan dan frekuensi yang divariasikan agar menghasilkan torka konstan. Analisis karakteristik motor induksi digunakan rangkaian pengganti dan perhitungan matematis. Untuk mengetahui rentan kerja mesin CNC maka arus starting 61,83Ampere; torka starting 23,28N.m; torka maksismum 14,1N.m; putaran sinkron $1500 \mathrm{rpm}$. Pengolahan data dilakukan secara matematis, pada pengukuran mendapatkan torka 35N.m sedangkan simulasi beban 30\% menghasilkan torka 4.2N.m; beban 60\% menghasilkan torka 8.3N.m; beban 90\% menghasilkan torka 12.5N.m. Dapat disimpulkan kendali V/f menghasilkan torka konstan sepanjang pengaturan kecepatan putar.
\end{abstract}

Kata kunci: PSIM, Variable Speed Drive, Torka Motor Induksi, Mesin CNC

\begin{abstract}
CNC machines are used to make aircraft frames, the induction motor as the driving force is set to rotate its speed to produce torque as needed, controlled by a variable speed drive. VSD control on CNC machines uses PSIM software to determine the characteristics of CNC machines with varied voltages and frequencies to produce constant torque. Analysis of the characteristics of the induction motor used a replacement circuit and mathematical calculations to determine the working range of the CNC machine. Then the starting current is 61.83Amperes; starting torque 23.28N.m; maximum torque $14.1 \mathrm{~N} . \mathrm{m}$; synchronous speed 1500rpm. Data processing is done mathematically, the measurement gets 35N.m of torque while the 30\% load simulation produces $4.2 \mathrm{~N} . \mathrm{m}$ of torque; $60 \%$ load produces $8.3 \mathrm{~N} . \mathrm{m}$ torque; $90 \%$ load produces $12.5 \mathrm{~N} . \mathrm{m}$ of torque. It can be concluded that the $\mathrm{V} / \mathrm{f}$ control produces constant torque throughout the rotational speed setting.
\end{abstract}

Keywords: PSIM, Variable Speed Drive, Induction Motor Torque, CNC Machine 


\section{PENDAhUlUAN}

PT. Dirgantara Indonesia memfokuskan salah satu bisnisnya di bidang Aerostructure. Bisnis satuan aerostructure memproduksi pengembangan rekayasa dan perencanaan (Indonesia, 2016).

Mesin CNC (ComputerNumericalContro/) paling banyak digunakan pada industri salah satunya adalah PT.Dirgantara Indonesia dengan menggunakan motor induksi sebagai mesin penggerak mesin CNC dalam proses pembuatan komponen di bidang aerostructure (Indonesia, 2016) (Jufrizaldy, Ilyas, \& Marzuki, 2020).

Mesin bubut CNC proses pemahatan benda kerja memerlukan kecepatan potong yang tetap agar hasil kerja memiliki tingkat presisi tinggi. Agar dapat menghasilkan benda yang halus, torka spindle pada saat pemotongan harus dijaga konstan, sedangkan pada saat pemotongan kecepatan spindle dapat berkurang yang diakibatkan naiknya torka beban (Permana \& Rameli, 2013).

Kendali V/f konstan merupakan salah satu cara untuk mengendalikan kecepatan putar motor induksi dengan merubah tegangan dan frekuensi, tetapi menjaga konstan rasio keduanya. Sehingga dengan cara kendali ini, torka yang dihasilkan dapat dijaga konstan sepanjang daerah pengaturan kecepatan. Hal yang paling umum dalam penerapan cara ini adalah dengan menggunakan perangkat yang dikenal sebagai inverter (Haryanto, 2011) (Atmam, Tanjung, \& Zulfahri, 2018).

PSIM merupakan software yang dirancang untuk elektronika daya dan kontrol motor (Powersim, 2020). Simulasi pada PSIM terdiri dari tiga program yaitu circuit schematic editor - SIMCAD, PSIM simulator, waveform processing - SIMVIEW (Asnil, 2013). Pada penelitian ini software PSIM digunakan untuk simulasi penggerak motor induksi yang di kopel dengan mesin CNC menggunakan pengendalian inverter sehingga mendapatkan karakteristik torka motor induksi pada mensin CNC. Rangkaian pengganti motor induksi digunakan untuk menentukan nilai torka dan nilai torka tersebut menjadi perbandingan dengan hasil simulasi software PSIM.

\section{METODE PENELITIAN}

\subsection{Diagram alir}

Gambar 1 merupakan alur metedologi yang digunakan secara singkat. Pengamatan dilapangan diketahui aliran proses penggunaan mesin CNC setelah itu menjabarkan latar belakang, merumuskan masalah. Pengumpulan data yaitu dengan pengukuran pada mesin CNC dan selanjutnya melakukan perhitungan matematis dan melakukan simulasi pada software PSIM. 

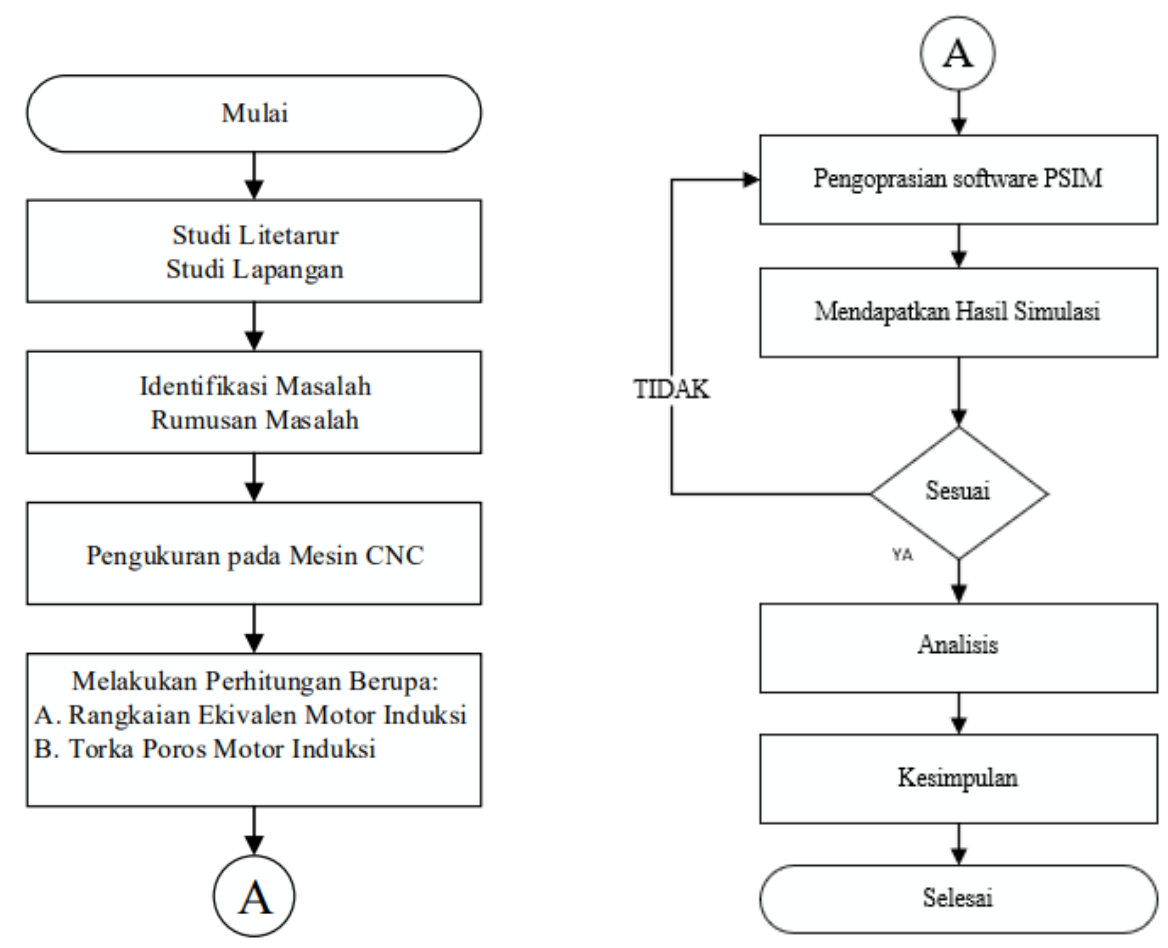

Gambar 1. Diagram Alir Metodelogi Penelitian

\subsection{Diagram Blok Sistem}

Gambar 2 merupakan perancanan sistematik yang akan dibuat secara umum.

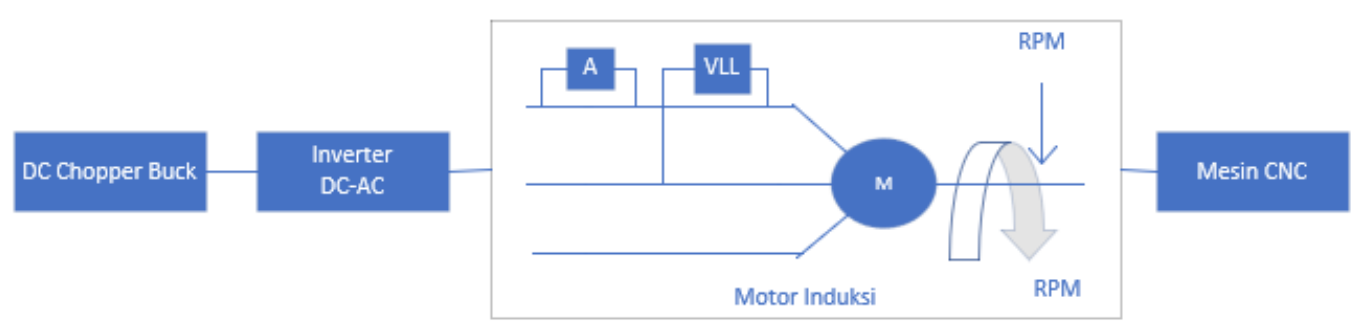

\section{Gambar 2. Blok Perencana Sistematik}

Gambar 2 DC Chopper Buck merupakan rangkaian untuk sumber tegangan output DC yang besarannya diatur sesuai dengan kebutuhan beban (Nurlana \& Murnomo, 2019). DC Chopper digunakan untuk tegangan masukkan pada inverter (Juarsah, Facta, \& Nugroho, 2015). Tegangan keluaran DC Chopper Buck akan masuk ke dalam inverter, disini inverter berfungsi sebagai rangkaian kontrol $\mathrm{V} / \mathrm{f}$ agar mendapatkan nilai output sesuai dengan kebutuhan produksi. Nilai tegangan dan frekuensi yang diatur tersebut lalu masuk ke motor induksi sebagai motor penggerak yang dikopel dengan mesin CNC sehingga mesin CNC mendapatkan beberapa nilai putaran yang dapat diatur pada mata bor (spindle).

\subsection{Chopper Buck}

DC Chopper Buck atau Buck Converter berfungsi untuk mengkonversi tegangan input searah yang diatur sesuai perubahan duty cycle sehingga tegangan arus searah menjadi sumber arus tegangan yang variable (Wibowo \& Facta, 2013) (Hushaini \& Hasan, 2019). Rangkaian DC Chopper Buck dibangun oleh komponen MOSFET, induktor, kapasitor dan resistor. Gambar 3 merupakan Rangkaian DC Chopper Buck pada simulasi PSIM. 


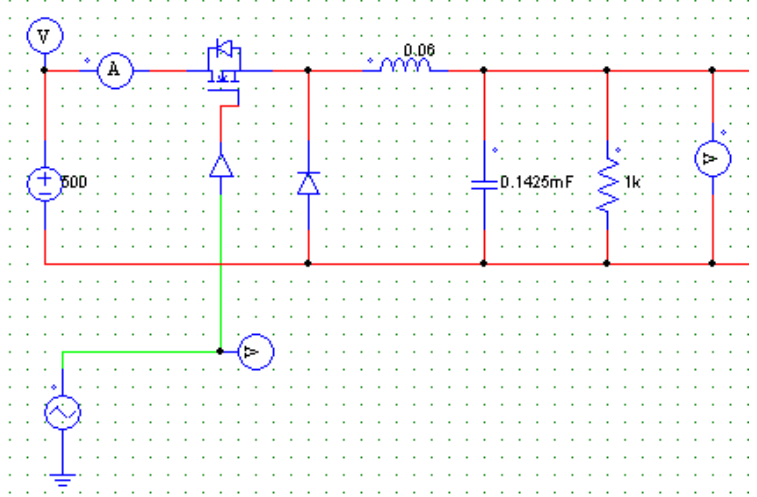

Gambar3. Rangkaian DC Chopper Buck

Untuk parameter dalam DC Chopper Buck digunakan persamaan:

Keterangan :

$$
D=\frac{\text { vout }}{\text { vin }}
$$

$$
\begin{array}{ll}
D & =\text { Duty Cycle (\%) } \\
\text { Vin } & =\text { Tegangan Input Buck Converter (Volt) } \\
\text { Vout } & =\text { Tegangan Output Buck Converter (Volt) }
\end{array}
$$

Menentukan nilai induktor :

$$
\begin{array}{ll}
\Delta I L & =\text { Ripple Arus Induktor (Ampere) } \\
\text { Iout } & =\text { Arus Output Konverter (Ampere) }
\end{array}
$$

Maka parameter induktansinya adalah sebagai berikut :

Keterangan:

$$
L=\frac{(\text { Vin-Vout }) \times \text { Vout }}{\text { F } x \Delta I L \times \text { Vin }}
$$

$$
\begin{array}{ll}
L & =\text { Induktansi }(\mathrm{H}) \\
\text { Vin } & =\text { Tegangan Input Buck Converter (Volt) } \\
\text { Vout } & =\text { Tegangan Output Buck Converter (Volt) } \\
F & =\text { Frekuensi Switching }(\mathrm{Hz}) \\
\Delta I L & =\text { Ripple Arus Induktor (Ampere) }
\end{array}
$$

Menentukan nilai kapasitor :

Keterangan:

$$
\Delta V o=5 \% \times \text { Vout }
$$

$\Delta V o \quad=$ Ripple Tegangan kapasitor (Volt)

Vout $\quad=$ Tegangan Output Konverter ( Volt $)$

Maka parameter kapasitansinya adalah sebagai berikut :

Keterangan :

$$
C=\frac{\Delta I L}{F \times \Delta V 0 \times 8}
$$

$C=$ Kapasitansi (Farad)

$\Delta V o=$ Ripple Tegangan kapasitor (Volt)

$F \quad=$ Frekuensi Switching $(\mathrm{Hz})$

\subsection{Perhitungan Rangkaian Ekivalen Motor Induksi}

Rangkaian pengganti dari rangkaian ekivalen satu phasa dari motor induksi yang dikopel dengan mesin CNC ditunjukan pada Gambar 4. 


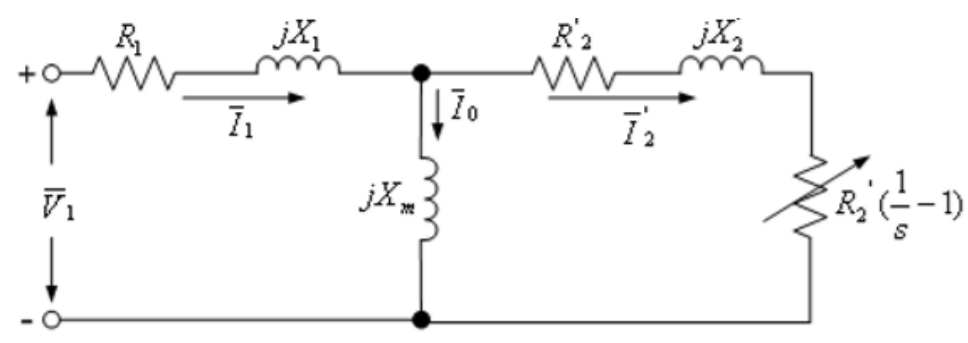

Gambar 4. Rangkaian Ekivalen perphasa dari Motor Induksi

Nilai parameter motor induksi sesuai dengan name plate dapat dilihat pada Tabel 1.

Tabel 1. Name Plate Motor Induksi

\begin{tabular}{|c|c|}
\hline Daya $(P)$ & $3 \mathrm{HP}$ \\
\hline Tegangan $($ Volt $)$ & $380 \mathrm{~V}$ \\
\hline Frekuensi $(\mathrm{f})$ & $50 \mathrm{~Hz}$ \\
\hline Phasa $(\mathrm{F})$ & 3 \\
\hline Pole $(\mathrm{p})$ & 4 \\
\hline Resistansi Rotor $\left(\mathrm{R}_{1}\right)$ & $0.249 \mathrm{ohm}$ \\
\hline Resistansu Stator $\left(\mathrm{R}_{2}\right)$ & $0.156 \mathrm{ohm}$ \\
\hline Induktansi Rotor $\left(\mathrm{X}_{2}\right)$ & $1.39 \mathrm{mH}$ \\
\hline Induktansi Stator $\left(\mathrm{X}_{1}\right)$ & $0.74 \mathrm{mH}$ \\
\hline Induktansi Gandeng $\left(\mathrm{X}_{\mathrm{m}}\right)$ & $41 \mathrm{mH}$ \\
\hline Momen inersia $(\mathrm{J})$ & $0.4 \mathrm{~kg} \cdot \mathrm{m}^{2}$ \\
\hline
\end{tabular}

$>$ Perhitungan tegangan Thevenin adalah:

$$
\begin{aligned}
V_{T H} & =V_{\emptyset} \frac{Z_{M}}{Z_{m}+Z_{1}} \\
V_{T H} & =V_{\emptyset} \frac{j X_{M}}{R_{1}+j X_{1}+j X_{M}} \\
V_{T H} & =V_{\emptyset} \frac{X_{M}}{\sqrt{R_{1}^{2}+\left(X_{1}+X_{M}\right)^{2}}}
\end{aligned}
$$

Keterangan:

$V_{T H}=$ Tegangan Thevenin (Volt)

$R_{1} \quad=$ Resistansi Stator

$X_{1}=$ Reaktans Stator

$X_{M}=$ Reaktans Magnetitasi

Perhitungan impedansi Thevenin adalah:

$$
\begin{aligned}
& Z_{T H}=\frac{Z_{1} \cdot Z_{M}}{Z_{1}+Z_{M}} \\
& Z_{T H}=R_{T H}+j X_{T H}=\frac{j X_{M}\left(R_{1}+j X_{1}\right)}{R_{1}+j\left(X_{1}+X_{M}\right)}
\end{aligned}
$$

Keterangan:

$Z_{T H}=$ Impedansi Theveni

$R_{T H}=$ TahananThevenin

$X_{T H}=$ Reaktansi Thevenin

$R_{1} \quad=$ Tahanan Stator $(\Omega)$

$X_{1}=$ Reaktansi Stator

$X_{M} \quad=$ Reaktansi Magnetitasi

$>$ Perhitungan slip pada torka maksimum adalah: 
Torka Motor Induksi pada Mesin CNC di PT.Dirgantara Indonesia Menggunakan Software PSIM

Keterangan:

$$
S_{\text {max }}=\frac{R_{2}}{\sqrt{R_{T H}^{2}+\left(X_{T H}+X_{2}\right)^{2}}}
$$

$S_{\text {max }}=$ Slip Maksimum

$R_{2} \quad=$ Tahanan Rotor

$R_{T H}=$ Resistansi Thevenin

Perhitungan dari kecepatan putaran sinkron adalah :

Keterangan:

$$
n_{\text {sync }}=\frac{f \times 120}{P}
$$

$$
\begin{aligned}
& n_{\text {sync }}=\text { Putaran Sinkron } \quad(\mathrm{rpm}) \\
& f \quad=\text { Frekuensi } \quad(\mathrm{Hz}) \\
& P \quad=\text { Pole }
\end{aligned}
$$

$>$ Perhitungan dari putaran sinkron adalah:

$$
\omega_{\text {sync }}=n_{\text {sync }} \times \frac{2 \pi \mathrm{rad}}{1 r} \times \frac{1 \mathrm{~min}}{60 \mathrm{~s}}
$$

Keterangan:

$$
\begin{aligned}
& \omega_{\text {sync }}=\text { Kecepatan Sudut ( } \quad(\mathrm{rad} / \mathrm{s}) \\
& n_{\text {sync }}=\text { Kecepatan Sinkron (rpm) }
\end{aligned}
$$

Perhitungan dari torka starting motor adalah :

Keterangan:

$$
T_{\text {Start }}=\frac{3 \times V_{T H}^{2} \times R_{2}}{\omega_{\text {sync }} x\left[\left(R_{T H}+R_{2}\right)^{2}+\left(X_{T H}+X_{2}\right)^{2}\right]}
$$

$$
\begin{array}{lll}
T_{\text {Start }}=\text { Torka Starting } & (\mathrm{N} . \mathrm{m}) \\
\omega_{\text {sync }}=\text { Kecepatan Sudut } & & (\mathrm{rad} / \mathrm{s}) \\
V_{T H} & =\text { Tegangan Thevenin } & (\text { Volt }) \\
R_{T H} & =\text { Resistansi Thevenin } & (\Omega) \\
X_{T H}=\text { Reaktansi Thevenin } & (\Omega) \\
R_{2}=\text { Tahanan Rotor } & (\Omega)
\end{array}
$$

$>$ Perhitungan dari torka maksimum motor adalah :

$$
T_{\text {max }}=\frac{3 x V_{T H}{ }^{2}}{2 x \omega_{\text {sync }} x\left[R_{T H}+\sqrt{R_{T H}^{2}+\left(X_{T H}+X_{2}\right)^{2}}\right]}
$$

Keterangan:

\begin{tabular}{lll}
$T_{\max }$ & $=$ Torka Maksimum & $(\mathrm{N} . \mathrm{m})$ \\
$\omega_{\text {sync }}$ & $=$ Kecepatan Sudut & $(\mathrm{rad} / \mathrm{s})$ \\
$V_{T H}$ & $=$ Tegangan Thevenin & $(\mathrm{Volt})$ \\
$R_{T H}$ & $=$ Resistansi Thevenin & $(\Omega)$ \\
$X_{T H}$ & $=$ Reaktansi Thevenin & $(\Omega)$ \\
$X_{2}$ & $=$ Reaktansi Rotor & $(\Omega)$ \\
\multicolumn{2}{l}{ Perhitungan dari arus starting adalah }
\end{tabular}

Keterangan:

$$
I_{\text {start }}=\frac{V_{T H}}{\sqrt{\left(R_{T H}+R_{2}\right)^{2}+\left(X_{T H}+X_{2}\right)^{2}}}
$$

$$
\begin{array}{ll}
I_{\text {start }} & =\text { Arus Starting } \\
V_{T H} & =\text { Tegangan Thevenin } \\
R_{T H} & =\text { Reaktansi Thevenin } \\
X_{T H} & =\text { Reaktansi Thevenin } \\
X_{2} & =\text { Reaktansi Rotor } \\
R_{2} & =\text { Tahanan Rotor }
\end{array}
$$

(Ampere)$$
\text { (Volt) }
$$ 


\subsection{Perhitungan Torka Poros Motor}

Torka merupakan suatu gaya yang dibutuhkan untuk memutar sebuah benda, sehingga benda tersebut berputar pada poros (Hariyanto, Saodah, \& Robby, 2016) (Chapman, 1991). Sebelum menghitung torka pada poros motor perlu diketahui perhitunganperhitungan seperti persamaan berikut ini.

$>$ Menghitung daya masukan motor menggunakan Persamaan (17) (Fizgerald, 1909):

$$
\begin{array}{ll}
\text { Keterangan: } \\
P_{i n} \quad=\text { Daya masukan (watt) } \\
V_{3 \varnothing} \quad=\text { Tegangan tiga phasa (volt) } \\
I_{\varnothing} \quad=\text { Arus (ampere) } \\
\cos \theta \quad=\text { Faktor daya }
\end{array}
$$$$
P=\sqrt{3} x V x I x \cos \varnothing
$$

$>$ Berdasarkan data name plate motor maka nilai $\eta$ sebesar $0.80 \%$ sehingga daya keluaran motor sebagai berikut ini:

Keterangan :

$$
P_{\text {out }}=\frac{P_{\text {in }} \times \eta}{100 \%}
$$

$$
\begin{array}{ll}
\eta & =\text { Efisiensi (\%) } \\
P_{\text {in }} & =\text { Daya masukan (Watt) } \\
P_{\text {out }} & =\text { Daya keluaran (Watt) }
\end{array}
$$

$>$ Untuk nilai slip pada motor, menggunakan Persamaan (19):

$$
s=\frac{N_{S}-N_{r}}{N_{S}} \times 100 \%
$$

Keterangan :

$$
\begin{array}{ll}
\text { Slip } & =\text { Slip (\%) } \\
n_{s} & =\text { Kecepatan sinkron (rpm) } \\
n_{r} & =\text { Kecepatan rotor (rpm) }
\end{array}
$$

> Untuk kecepatan poros mekanik pada rotor, menggunakan Persamaan (20) :

Keterangan :

$$
\omega_{m}=(1-\operatorname{slip}) x \omega_{\text {sync }}
$$

$\omega_{m} \quad=$ Kecepatan poros mekanik (rad/s)

$\omega_{\text {sync }} \quad=$ Kecepatan sinkron (rad/s)

Sedangkan, untuk torka beban yang terjadi pada motor dihitung dengan Persamaan (21):

Keterangan:

$$
T_{L}=\frac{P_{o}}{\left(\frac{2 \pi}{60}\right) \cdot n_{r}}
$$

$T_{L}=$ Torka beban motor (N.m)

Dengan asumsi $\frac{d w}{d t}=0.1 \mathrm{rad} / \mathrm{s}$, sehingga untuk menghitung torka dinamik yang terjadi pada motor dapat dihitung dengan menggunakan persamaan berikut ini (Desphande, 1990):

$$
T_{d}=J_{T} \frac{d w}{d t}
$$

Keterangan :

$T_{d} \quad=$ Torka dinamik motor (N.m)

$J_{T} \quad=$ Momen inersia dari sistem penggerak $\left(\mathrm{Kg} \cdot \mathrm{m}^{2}\right)$

$\omega \quad=$ Kecepatan sudut dalam mekanik (rad/s)

Sehingga untuk menghitung torka motor yang dibutuhkan motor ketika diberikan beban dapat dihitung menggunakan persamaan, berikut ini :

Keterangan:

$$
T_{m}=T_{L}+T_{d}
$$

$T_{m}=$ Torka motor (N.m) 


\subsection{Rangkaian Variable Speed Drive pada PSIM}

Gambar rangkaian variable speed drive ditunjukkan pada Gambar 5.

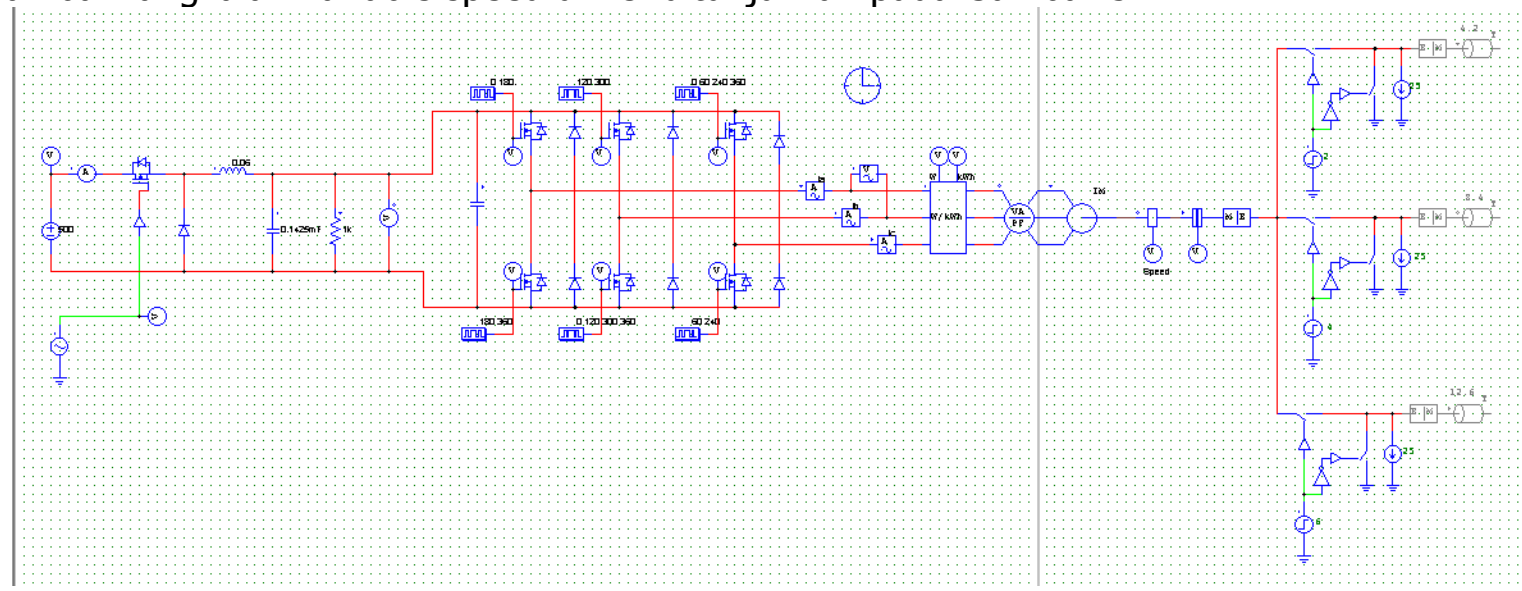

Gambar 5. Rangkaian Variable Speed Drive pada PSIM

Pada Gambar 5 rangkaian variable speed drive untuk mendapatkan kecepatan putaran dan torsi motor. Tegangan DC dialirkan ke board DC Chopper Buck dimana tegangan DC menajdi tegangan arus yang bersifat variable. Berdasarkan Persamaan (1) - (5) maka parameter Chopper Buck ditunjukan pada Tabel 2.

Tabel 2. Parameter DC Chopper Buck

\begin{tabular}{|c|c|c|}
\hline Parameter & Simbol & Nilai \\
\hline Tegangan Input & Vin & $500 \mathrm{~V}-\mathrm{DC}$ \\
\hline Arus Output & $I_{S c}$ & $5 \mathrm{~A}$ \\
\hline Riak Arus & $\Delta I$ & $5 \%$ \\
\hline Riak Tegangan & $\Delta V$ & $5 \%$ \\
\hline Frekuensi Switching & $\mathrm{f}$ & $20 \mathrm{kHz}$ \\
\hline
\end{tabular}

Tegangan keluaran dari DC Chopper Buck merupakan tegangan masukan inverter, dimana rasio tegangan dan frekuensi harus dijaga seimbang dengan merubah duty cycle pada DC Chopper Buck. Kontrol V/f pada inverter ditunjukkan pada Tabel 3.

Tabel 3. Kontrol V/f

\begin{tabular}{|c|c|c|}
\hline $\begin{array}{c}\text { Tegangan } \\
\text { Output DC Buck } \\
\text { (Volt) }\end{array}$ & Duty Cycle. & $\begin{array}{c}\text { Frekuensi } \\
\text { (Hz) }\end{array}$ \\
\hline 360 & 0.7 & 40 \\
\hline 405 & 0.8 & 45 \\
\hline 450 & 0.9 & 50 \\
\hline
\end{tabular}

Setelah itu tegangan DC dicacah dan dimodulasi sehingga menjadi tegangan AC lalu dialirkan ke motor induksi tiga phasa. Motor induksi kemudian dikopel dengan mesin CNC, pada mesin CNC akan dilakukan pembebanan sebesar 30\%, 60\% dan 90\%. Adapun nilai parameter-parameter pada rangkaian motor induksi tiga phasa sesuai dengan name plate dalam simulasi software PSIM ditunjukkan pada Tabel 4. 
Tabel 4. Name Plate Motor Induksi pada PSIM

\begin{tabular}{|c|c|}
\hline Daya $(P)$ & $3 \mathrm{HP}$ \\
\hline Tegangan (Voly) & $380 \mathrm{~V}$ \\
\hline Frekuensi $(\mathrm{f})$ & $50 \mathrm{~Hz}$ \\
\hline Phasa $(\mathrm{F})$ & 3 \\
\hline Pole $(\mathrm{p})$ & 4 \\
\hline Resistansi Rotor $\left(\mathrm{R}_{1}\right)$ & $0.249 \mathrm{ohm}$ \\
\hline Resisitansi Stator $\left(\mathrm{R}_{2}\right)$ & $0.156 \mathrm{ohm}$ \\
\hline Induktansi Rotor $\left(\mathrm{X}_{2}\right)$ & $1.39 \mathrm{mH}$ \\
\hline Induktansi Stator $\left(\mathrm{X}_{1}\right)$ & $0.74 \mathrm{mH}$ \\
\hline Induktansi Gandeng $\left(\mathrm{X}_{\mathrm{m}}\right)$ & $41 \mathrm{mH}$ \\
\hline Momen inersia $(\mathrm{J})$ & $2 \mathrm{~kg} \cdot \mathrm{m}^{2}$ \\
\hline
\end{tabular}

\section{HASIL DAN PEMBAHASAN}

\subsection{Data Perhitungan Rangkaian Ekivalen Motor Induksi}

Tabel 5 merupakan data mengukuran motor induksi pada mesin CNC.

Tabel 5. Data Pengukuran Motor Induksi pada Mesin CNC

\begin{tabular}{|c|c|c|c|c|c|}
\hline NO & $\begin{array}{c}\text { Tegangan } \\
\text { Phasa phasa } \\
(\text { Volt })\end{array}$ & $\begin{array}{c}\text { Frekuensi } \\
(\mathrm{Hz})\end{array}$ & $\begin{array}{c}\text { Arus } \\
\text { Input } \\
(\mathrm{A})\end{array}$ & $\begin{array}{c}\text { Kecepatan } \\
\text { Putar } \\
(\mathrm{RPM})\end{array}$ & $\begin{array}{c}\text { Efesiensi } \\
\text { Motor (\%) }\end{array}$ \\
\hline 1 & 110.75 & 50 & 15.5 & 510 & 80 \\
\hline 2 & 138.58 & 50 & 17.7 & 750 & 80 \\
\hline 3 & 170.53 & 50 & 18.8 & 980 & 80 \\
\hline 4 & 187.62 & 50 & 19.9 & 1100 & 80 \\
\hline 5 & 202.64 & 50 & 23.7 & 1420 & 80 \\
\hline
\end{tabular}

Hasil pengukuran pada Tabel 5 maka dilakukan perhitungan matematis torka pada poros motor sesuai dengan Persamaan (17) - (23). Berikut adalah Tabel 6 data hasil perhitungan matematis torka motor induksi.

Tabel6. DataPerhitungan Matematis Torka Motor Induksi

\begin{tabular}{|c|c|c|c|c|c|c|c|}
\hline $\begin{array}{c}\text { Daya } \\
\text { Input } \\
\text { (Watt) }\end{array}$ & $\begin{array}{c}\text { Daya } \\
\text { Output } \\
\text { (Watt) }\end{array}$ & Slip & $\begin{array}{c}\text { Kecepatan } \\
\text { Rotor } \\
\omega_{\mathrm{m}} \\
(\mathrm{rad} / \mathrm{s})\end{array}$ & $\begin{array}{c}\text { Torka } \\
\text { Load } \\
(\mathrm{N} . \mathrm{m})\end{array}$ & $\begin{array}{c}\text { Percepatan } \\
\text { Dinamik } \\
\text { Motor } \\
(\text { N.m) }\end{array}$ & $\begin{array}{c}\text { Torka } \\
\text { Dinamik } \\
(\mathrm{N} . \mathrm{m})\end{array}$ & $\begin{array}{c}\text { Torka } \\
\text { Motor } \\
(\mathrm{N} . \mathrm{m})\end{array}$ \\
\hline 2379 & 1903 & 0.7 & 510 & 35 & 0.1 & 0.2 & 35.2 \\
\hline 3399 & 2719 & 0.5 & 750 & 34 & 0.1 & 0.2 & 34.2 \\
\hline 4442 & 3554 & 0.3 & 980 & 34 & 0.1 & 0.2 & 34.2 \\
\hline 5173 & 4139 & 0.3 & 1100 & 35 & 0.1 & 0.2 & 34.2 \\
\hline 6655 & 5324 & 0.1 & 1420 & 3.5 & 0.1 & 0.2 & 34.2 \\
\hline
\end{tabular}

\subsection{Perhitungan Rangkaian Ekivalen Motor Induksi Satu Phasa}

Perhitungan rangkaian ekivalen motor induksi satu phasa ditunjukkan pada Tabel 7. 
Tabel 7. Hasil Perhitungan Rangkaian Ekivalen Motor Induksi Satu Phasa

\begin{tabular}{|c|c|c|}
\hline No & Perhitungan & Nilai \\
\hline 1 & $\mathrm{~V}_{\mathrm{TH}}$ & 21,56 Volt \\
\hline 2 & $\mathrm{R}_{\mathrm{TH}}$ & $0,089 \Omega$ \\
\hline 3 & $\mathrm{X}_{\mathrm{TH}}$ & $8,87 \times 10^{-5} j \Omega$ \\
\hline 4 & $\mathrm{Z}_{\mathrm{TH}}$ & $0,089+8,87 \times 10^{-5} j \Omega$ \\
\hline 5 & $\mathrm{~S}_{\mathrm{Max}}$ & 10,76 \\
\hline 6 & $\mathrm{n}_{\text {sync }}$ & $1500 \mathrm{Rpm}$ \\
\hline 7 & $\omega_{\text {sync }}$ & $50 \Pi \mathrm{rad} / \mathrm{s}$ \\
\hline 8 & $\mathrm{~T}_{\text {start }}$ & $7,76 \mathrm{~N} . \mathrm{m}$ \\
\hline 9 & $\mathrm{~T}_{\max }$ & $4,7 \mathrm{~N} . \mathrm{m}$ \\
\hline 10 & $\mathrm{I}_{\text {start }}$ & $20,61 \mathrm{~A}$ \\
\hline
\end{tabular}

\subsection{Pengujian dengan Software PSIM}

Simulasi dengan software PSIM berdasarkan Gambar 5 maka didapatkan hasil output berupa grafik karakteristk motor induksi tiga fasa yang beroperasi pada mesin CNC, hasil grafik karakteristiknya sebagai berikut:

\section{a. Tegangan 487 Volt dan Frekuensi $50 \mathrm{~Hz}$}

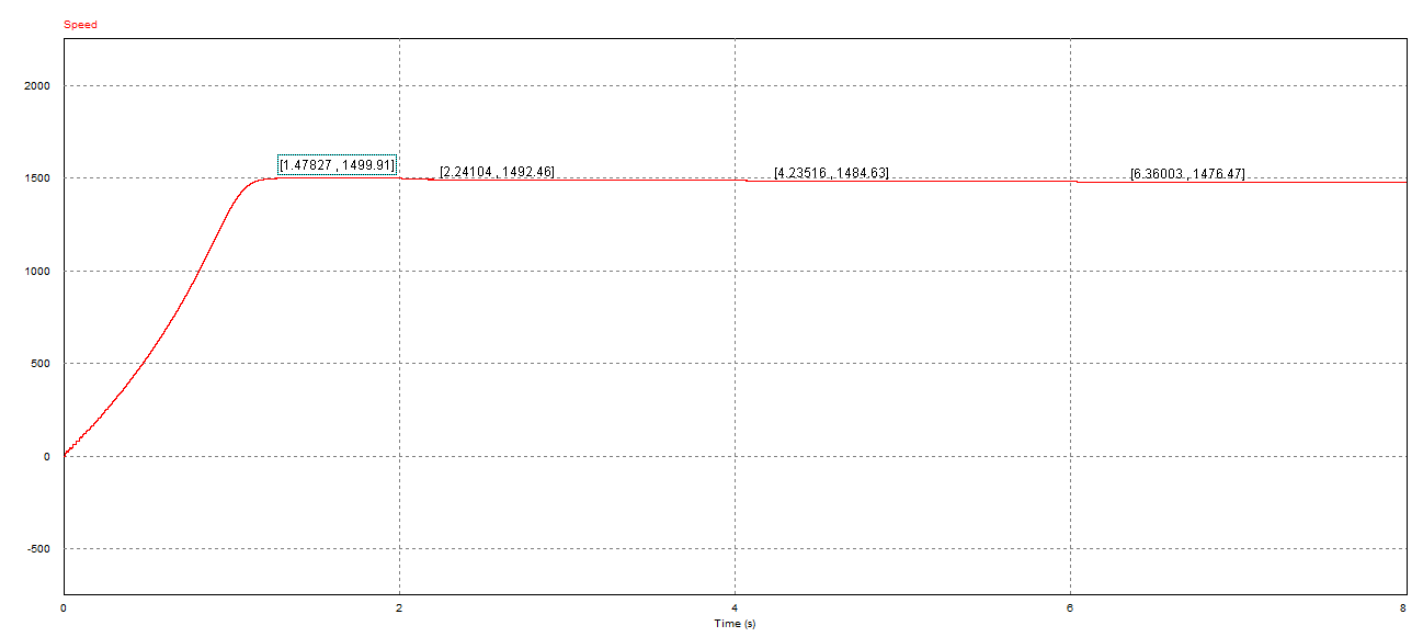

Gambar 6. Grafik Kecepatan pada Tegangan 487 V dan Frekuensi 50 Hz

Pada Gambar 6 saat motor dijalankan (starting) kecepatan putaran motor berubah dari nol mendekati nilai sinkronnya. Kecepatan putar bergerak dari 0 menuju 1499rpm kondisi mantap (steady state) pada waktu 0 sampai 2 detik dengan beban $0 \%$. Saat beban di naikan 30\% dengan peralihan transien selama 0.2 detik kecepatan akan menurun sampai $1492 \mathrm{rpm}$. Pada waktu 4 detik beban di naikan $60 \%$ kecepatan menurun pada waktu 4.2 detik sebesar $1484 \mathrm{rpm}$. Kemudian pada waktu 6 detik beban di naikan 90\% dengan peralihan transien selama 0.2 detik kecepatan akan menurun sampai $1476 \mathrm{rpm}$. 


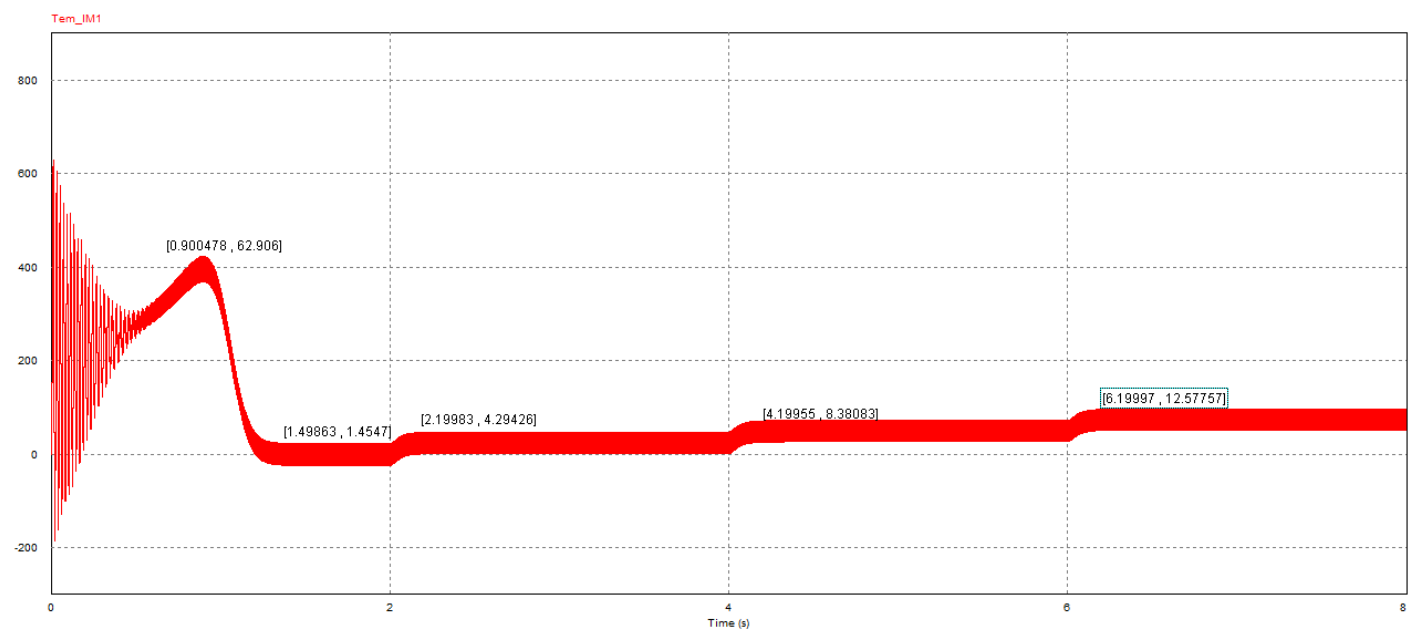

Gambar 7. Grafik Torka pada Tegangan 487 V dan Frekuensi 50 Hz

Dapat dilihat Gambar 7 saat motor dijalankan (starting) torka elektromagnetik mencapai 62 N.m pada waktu 0.0133 detik, pengasutan torka elektromagentik untuk mencapai kondisi mantap (steady state) membutuhkan waktu 1.5detik dengan beban $0 \%$ dengan torka sebesar $0.2 \mathrm{~N} . \mathrm{m}$. Ketika beban di naikan transien peralihan selama 0.2 detik, sehingga pada waktu 2.2 detik dengan beban $30 \%$ torka sebesar 4.2 N.m, pada waktu 4.4 detik dengan beban $60 \%$ torka sebesar 8.3 N.m dan pada waktu 6.2 detik dengan beban $90 \%$ torka sebesar 12.5 N.m.

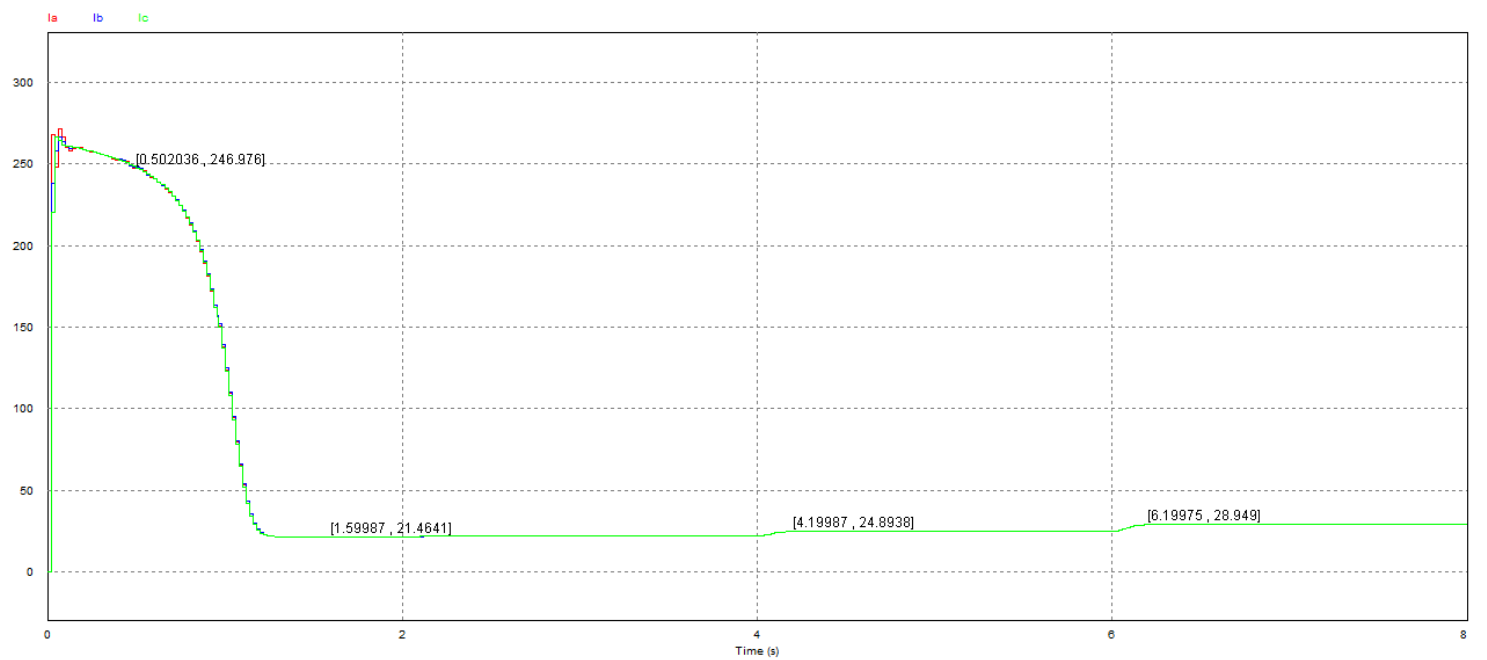

Gambar 8. Grafik Arus pada Tegangan 487 V dan Frekuensi $50 \mathrm{~Hz}$

Berdasarkan Gambar 8 dapat dilihat bahwa pada saat motor dijalankan (starting) nilai arus mencapai 250 A pada waktu 0.1 detik, pengasutan nilai arus hingga kondisi kondisi mantap (steady state) dengan beban $0 \%$ sebesar $21 \mathrm{~A}$ pada waktu 1.5 detik. Peralihan transien pada perubahan beban membutuhkan waktu selama 0.2 detik. Ketika beban $30 \%$ pada waktu 2.2 detik nilai arus sebesar 22 A, selanjutnya beban dinaikan $30 \%$ pada waktu 4.2 detik nilai arus sebesar $24 \mathrm{~A}$ dan beban $90 \%$ pada waktu 6.2 detik nilai arus sebesar $28 \mathrm{~A}$. 


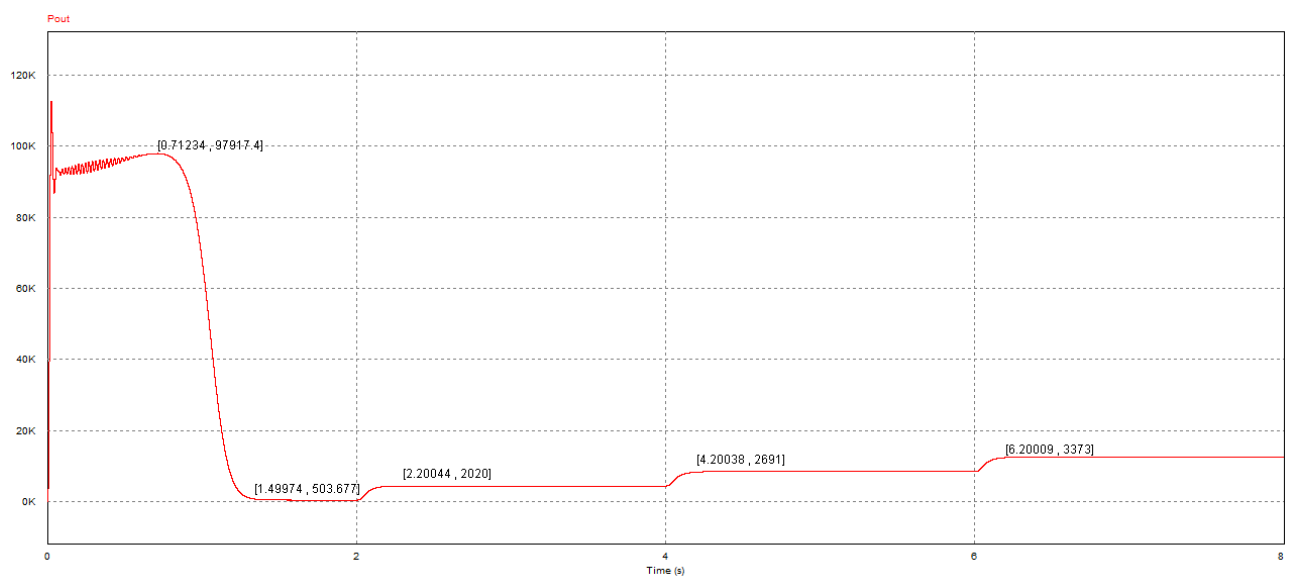

Gambar 9. Grafik Daya pada Tegangan 487 V dan Frekuensi $50 \mathrm{~Hz}$

Berdasarkan Gambar 9 nilai daya output inverter sama dengan daya input motor pada saat motor dijalankan (starting) nilai daya mencapai 11.264 Watt pada waktu 0.02 detik, pengasutan nilai daya hingga kondisi mantap (steady state) dengan beban 0\% sebesar 2000 Watt pada waktu 1.5 detik. Perlihan transien pada perubahan beban membutuhkan waktu selama 0.2 detik. Ketika beban $30 \%$ pada waktu 2.2 detik nilai daya sebesar 2020 Watt, selanjutnya beban dinaikan 30\% pada waktu 4.2 detik nilai daya sebesar 2691 Watt dan beban $90 \%$ pada waktu 6.2 detik nilai daya sebesar 3373 Watt.

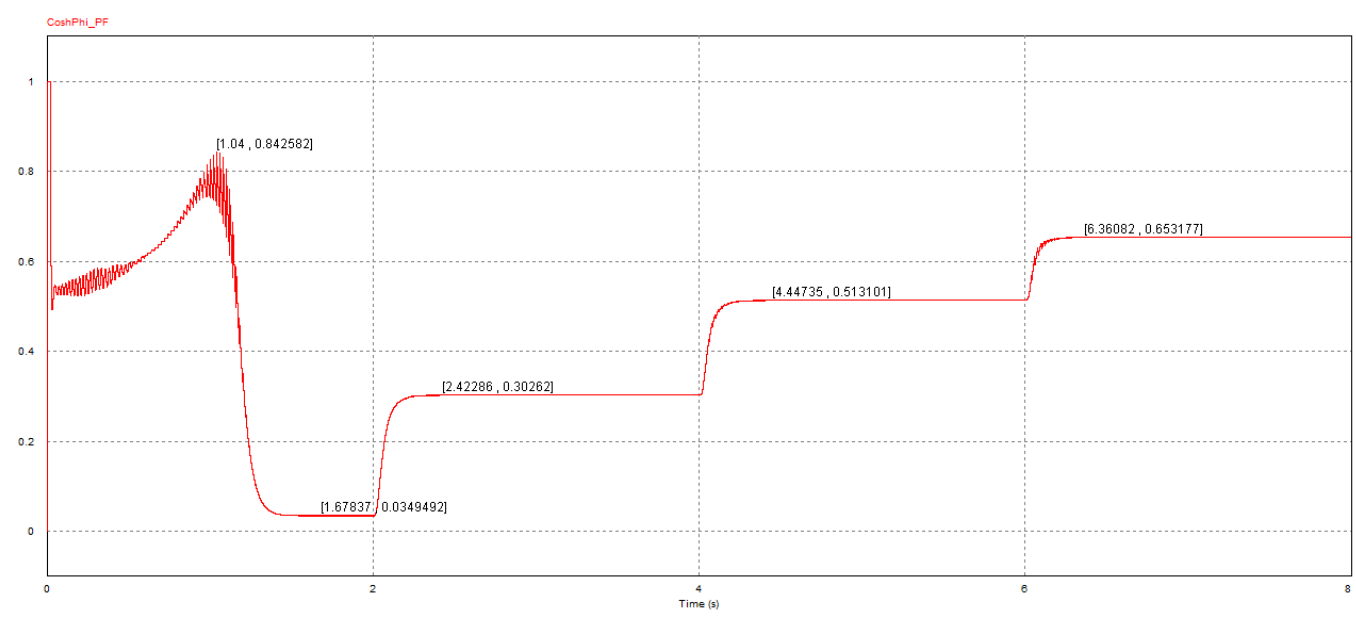

Gambar 10. Grafik Cosh Phi pada Tegangan 487 V dan Frekuensi $50 \mathrm{~Hz}$

Pada Gambar 10 saat motor dijalankan (starting) nilai cosh phi mencapai 0.8 Pf pada waktu 0.01 detik, pengasutan nilai daya hingga kondisi mantap (steady state) dengan beban $0 \%$ sebesar 0.003 Pf pada waktu 1.5 detik. Perlihan transien pada perubahan beban membutuhkan waktu selama 0.2 detik. Ketika beban $30 \%$ pada waktu 2.2 detik nilai daya sebesar $0.3 \mathrm{Pf}$, selanjutnya beban dinaikan $30 \%$ pada waktu 4.2 detik nilai daya sebesar 0.6 Pf dan beban $90 \%$ pada waktu 6.2 detik nilai daya sebesar 0.6 Pf.

Berdasarkan simulasi menggunakan software PSIM, maka data hasil simulasi beban $30 \%$ ditunjukan pada Tabel 8. 
Tabel 8. Data Simulasi Beban 30\%

\begin{tabular}{|c|c|c|c|c|c|c|c|c|c|c|}
\hline $\begin{array}{c}\text { Vo DC } \\
\text { Buck } \\
\text { (Volt) }\end{array}$ & $\begin{array}{c}\mathbf{F} \\
(\mathbf{H z})\end{array}$ & $\begin{array}{c}\text { VLL } \\
\text { (Volt) }\end{array}$ & $\begin{array}{c}\text { Arus } \\
\text { (A) }\end{array}$ & $\begin{array}{c}\text { Daya } \\
\text { Input } \\
\text { (Watt) }\end{array}$ & $\begin{array}{c}\text { Kecepatan } \\
\text { (RPM) }\end{array}$ & $\begin{array}{c}\text { Cosh } \\
\text { PHI }\end{array}$ & $\begin{array}{c}\text { Torka } \\
\text { (N.m) }\end{array}$ & $\begin{array}{c}\text { Daya } \\
\text { Output } \\
\text { (Watt) }\end{array}$ & $\begin{array}{c}\mathbf{n} \\
(\mathbf{\%})\end{array}$ & Slip \\
\hline 450 & 50 & 380 & 21 & 2020 & 1492 & 0.3 & 4.2 & 656 & 0.3 & 0.1 \\
\hline 405 & 45 & 342 & 24 & 1882 & 1342 & 0.3 & 4.2 & 590 & 0.3 & 0.11 \\
\hline 360 & 40 & 306 & 28 & 1747 & 1192 & 0.3 & 4.2 & 524 & 0.3 & 0.21 \\
\hline
\end{tabular}

Dari hasil simulasi menggunakan software PSIM, maka data hasil simulasi beban $60 \%$ ditunjukan pada Tabel 9.

Tabel 9. Data Simulasi Beban $60 \%$

\begin{tabular}{|c|c|c|c|c|c|c|c|c|c|c|}
\hline $\begin{array}{c}\text { Vo DC } \\
\text { Buck } \\
\text { (Volt) }\end{array}$ & $\begin{array}{c}\text { F } \\
(\mathbf{H z})\end{array}$ & $\begin{array}{c}\text { VLL } \\
\text { (Volt) }\end{array}$ & $\begin{array}{c}\text { Arus } \\
(\mathbf{A})\end{array}$ & $\begin{array}{c}\text { Daya } \\
\text { Input } \\
\text { (Watt) }\end{array}$ & $\begin{array}{c}\text { Kecepatan } \\
\text { (RPM) }\end{array}$ & $\begin{array}{c}\text { Cosh } \\
\text { PHI }\end{array}$ & $\begin{array}{c}\text { Torka } \\
\text { (N.m) }\end{array}$ & $\begin{array}{c}\text { Daya } \\
\text { Output } \\
\text { (Watt) }\end{array}$ & $\begin{array}{c}\text { n } \\
(\mathbf{\%})\end{array}$ & Slip \\
\hline 450 & 50 & 380 & 21 & 2691 & 1484 & 0.5 & 8.3 & 1289 & 0.5 & 0.01 \\
\hline 405 & 45 & 342 & 24 & 2485 & 1334 & 0.5 & 8.3 & 1159 & 0.5 & 0.11 \\
\hline 360 & 40 & 306 & 28 & 2004 & 1184 & 0.5 & 8.3 & 1029 & 0.5 & 0.21 \\
\hline
\end{tabular}

Dari hasil simulasi menggunakan software PSIM, maka data hasil simulasi beban $90 \%$ ditunjukan pada Tabel 10.

Tabel 10. Data Simulasi Beban $90 \%$

\begin{tabular}{|c|c|c|c|c|c|c|c|c|c|c|}
\hline $\begin{array}{c}\text { Vo DC } \\
\text { Buck } \\
\text { (Volt) }\end{array}$ & $\begin{array}{c}\mathbf{F} \\
\mathbf{( H z )}\end{array}$ & $\begin{array}{c}\text { VLL } \\
\text { (Volt) }\end{array}$ & $\begin{array}{c}\text { Arus } \\
\text { (A) }\end{array}$ & $\begin{array}{c}\text { Daya } \\
\text { Input } \\
\text { (Watt) }\end{array}$ & $\begin{array}{c}\text { Kecepatan } \\
\text { (RPM) }\end{array}$ & $\begin{array}{c}\text { Cosh } \\
\text { PHI }\end{array}$ & $\begin{array}{c}\text { Torka } \\
\text { N.m }\end{array}$ & $\begin{array}{c}\text { Daya } \\
\text { (Watt) }\end{array}$ & $\begin{array}{c}\mathbf{n} \\
\mathbf{( \% )}\end{array}$ & Slip \\
\hline 450 & 50 & 380 & 28 & 3373 & 1476 & 0.6 & 12.5 & 1931 & 0.6 & 0.02 \\
\hline 405 & 45 & 342 & 28 & 3101 & 1326 & 0.6 & 12.5 & 1734 & 0.6 & 0.12 \\
\hline 360 & 40 & 306 & 30 & 2519 & 1176 & 0.6 & 12.5 & 1538 & 0.6 & 0.22 \\
\hline
\end{tabular}

\subsection{Analisis}

Berikut adalah analisis sesuai dengan hasil penelitian:

Pada simulasi PSIM saat motor starting dengan kondisi tanpa beban sampai motor beroperasi secara normal, kecepatan putaran rotor akan berubah dari nol sampai mendekati kecepatan sinkronnya. Pada frekuensi $50 \mathrm{~Hz}$ kecepatan sinkron mencapai 1499rpm, pada frekuensi $45 \mathrm{~Hz}$ kecepatan sinkron sebesar $1350 \mathrm{rpm}$, sedangkan pada frekuensi minimum $40 \mathrm{~Hz}$ kecepatan sinkron mencapai $1200 \mathrm{rpm}$. Nilai frekuensi berbanding lurus dengan arus yang masuk pada kumparan sehingga fluks magnet terjadi gaya gerak listrik (GGL) maka rotor akan berputar. Perubahan pada kecepatan rotor menyebabkan terjadinya perubahan slip (S) dari satu menjadi lebih kecil dari satu. Nilai slip pada frekuensi $50 \mathrm{~Hz}$ sebesar 0.01 , pada frekuensi $45 \mathrm{~Hz}$ sebesar 0.1 dan pada frekuensi $40 \mathrm{~Hz}$ sebesar 0.21 . Perubahan nilai slip (S) akan menyebabkan perubahan nilai arus, torka dan kecepatan. Nilai slip (S) pada saat motor dijalankan sama dengan satu, sedangkan pada kondisi steady state harga slip (S) lebih kecil dari satu. Saat motor mulai dijalankan akan lebih keclil dari kondisi steady state, sehingga arus dan torka pada kondisi saat mulai dijalankan (starting) akan lebih besar bila dibandingkan dengan kondisi steady state. 


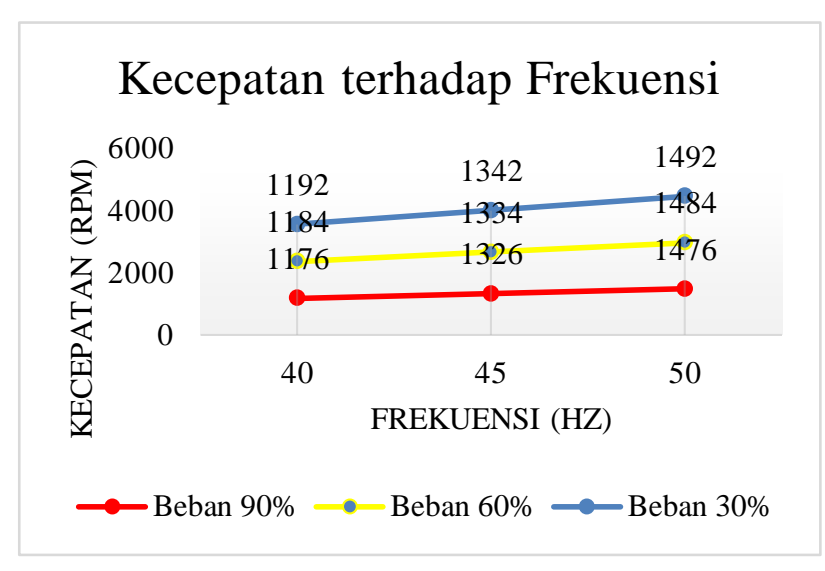

(a)

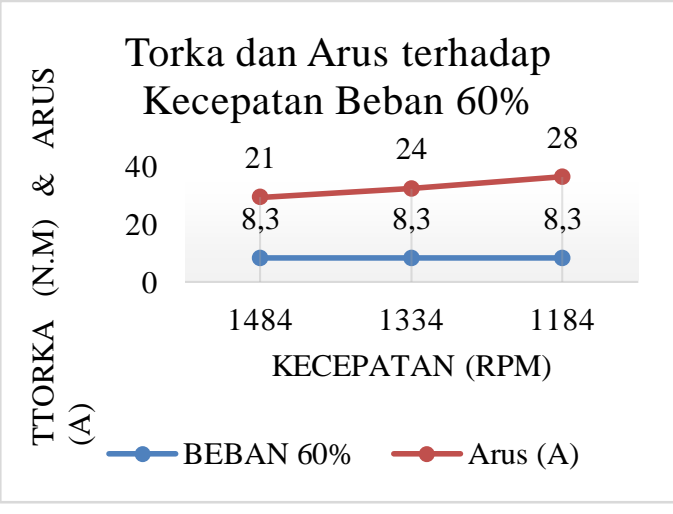

(c)

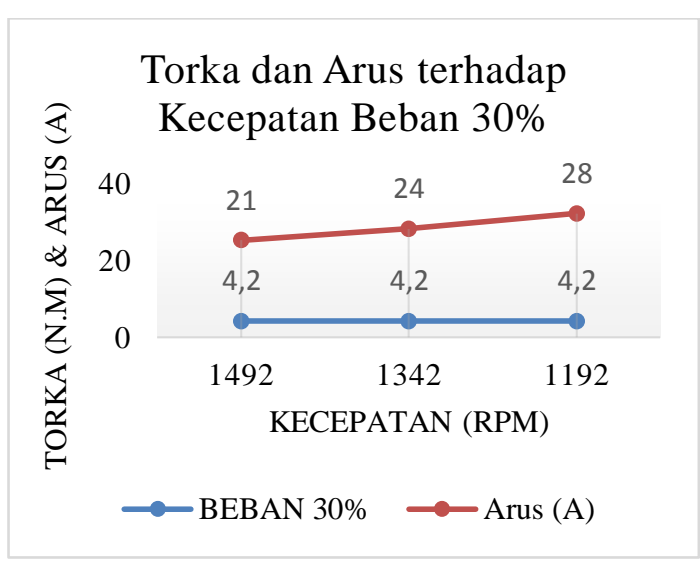

(b)

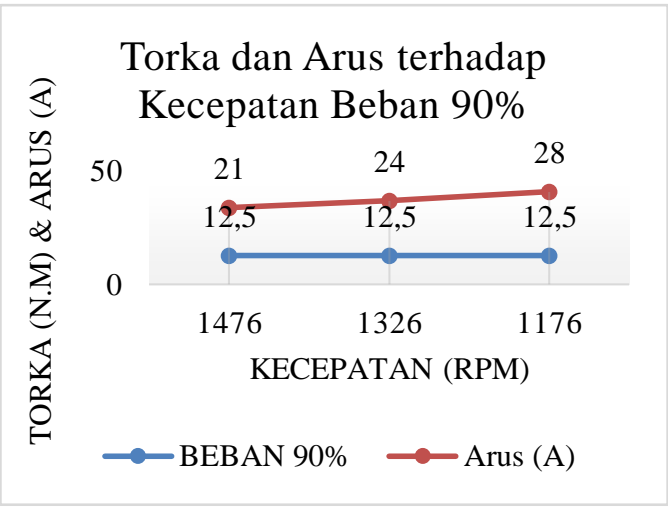

(d)

\section{Gambar 11. (a)Kecepatan terhadap Frekuensi; (b). Torka dan Arus terhadap Kecepatan Beban 30\%; (c).Torka dan Arus terhadap Kecepatan Beban 60\%; (d). Torka dan Arus terhadap Kecepatan Beban 90\%}

Saat diberi beban $30 \%, 60 \%$ dan $90 \%$ maka akan terjadi penurunan kecepatan putar rotor. Berdasarkan Gambar 10.(a) dapat dilihat garis berwarna biru merupakan kecepatan dengan beban $30 \%$, pada frekuensi $40 \mathrm{~Hz}$ kecepatan mencapai $1192 \mathrm{rpm}$, frekuensi $45 \mathrm{~Hz}$ kecepatan mencapai $1342 \mathrm{rpm}$ dan frekuensi $50 \mathrm{~Hz}$ kecepatan mencapai 1492. Untuk garis berwarna kuning merupakan kecepatan dengan beban $60 \%$ dimana pada frekuensi $40 \mathrm{~Hz}$ kecepatan mencapai $1184 \mathrm{rpm}$, frekuensi $40 \mathrm{~Hz}$ kecepatan mencapai $1334 \mathrm{rpm}$ dan frekuensi $50 \mathrm{~Hz}$ kecepatan mencapai $1484 \mathrm{rpm}$. Sedangkan garis berwarna merah merupakan kecepatan dengan beban $90 \%$ dimana pada frekuensi $40 \mathrm{~Hz}$ kecepatan mencapai $1176 \mathrm{rpm}$, frekuensi $45 \mathrm{~Hz}$ kecepatan mencapai $1326 \mathrm{rpm}$ dan frekuensi $50 \mathrm{~Hz}$ kecepatan mencapai $1476 \mathrm{rpm}$. Nilai slip menjadi lebih besar setelah beroperasi secara normal menyebabkan Penurunan kecepatan pada kondisi berbeban. Kenaikan slip ini akan berpengaruh terhadap daya, motor membutuhkan daya yang sangat besar untuk menggerakan motor pada saat kondisi diam dengan beban dan slip yang besar sehingga nilai cosh phi pada motor akan bertambah besar. Namun pada arus dan torka akan mengalami kenaikan, berdasarkan Gambar 10(b) sampai dengan Gambar 10 (c) nilai arus dan torka akan naik seiring bertambahnya beban. Nilai arus pada frekuensi $40 \mathrm{~Hz}$ sebesar $21 \mathrm{~A}$, pada frekuensi $45 \mathrm{~Hz}$ sebesar $24 \mathrm{~A}$ dan frekuensi $50 \mathrm{~Hz}$ sebesar $28 \mathrm{~A}$. Sedangkan untuk nilai torka dengan beban $30 \%$ sebesar 4.2 N.m, dengan beban $60 \%$ sebesar $8.3 \mathrm{~N} . \mathrm{m}$ dan beban $90 \%$ sebesar $12.5 \mathrm{~N} . \mathrm{m}$. Nilai torka tersebut akan selalu konstan sepanjang daerah pengaturan kecepatan motor. Nilai torka konstan terjadi karena pengaturan tegangan dan frekuensi yang seimbang pada inverter. 


\section{KESIMPULAN}

Hasil penelitian dapat disimpulkan variable speed drive dengan kendali $V / f$ akan mempengaruhi kinerja motor induksi. Berdasarkan persamaan 12 kecepatan motor induksi berbanding lurus dengan frekuensi sumber daya dan jumblah kutub dari motor. Pembebanan akan berpengaruh terhadap kecepatan rotor. Semakin besar beban maka nilai torka akan besar dan kecepatan akan menurun hal itu disebabkan pengaruh nilai slip. Nilai slip pada frekuensi $50 \mathrm{~Hz}$ sebesar 0.01 , pada frekuensi $45 \mathrm{~Hz}$ sebesar 0.1 dan pada frekuensi $40 \mathrm{~Hz}$ sebesar 0.21 . Dengan kendali $\mathrm{V} / \mathrm{f}$ konstan pada inverter, tegangan dan frekuensi dijaga konstan seiring laju kecepatan putar yang diatur. maka pada pembebanan sebesar $30 \%$ menghasilan torka konstan sebesar 4.2 N.m, sedangkan pada beban $60 \%$ menghasilkan torka kontan sebesar $8.3 \mathrm{~N} . \mathrm{m}$, dan pada beban $90 \%$ meghasilkan torka konstan sebesar 12.5 N.m. Pemodelan simulasi pada PSIM dilakukan untuk mengetahui perbandingan antara hasil simulasi, perhitungan dan pengukuran untuk memperoleh torka konstan dengan pengaturan kecepatan putar pada mesin CNC yang dikendalikan oleh variable speed drive.

\section{UCAPAN TERIMA KASIH}

Penulis mengucapkan terimakasih kepada PT.Dirgantara Indonesia telah memberikan kesempatan untuk melaksanakan penelitian serta penulis mengucapkan terimakasih kepada keluarga yang selalu memberi dukungan secara moral dan materil kepada penulis.

\section{DAFTAR PUSTAKA}

Asnil. (2013). Applikasi Perangkat Lunak Simulasi sebagai Alat Bantu untuk Mempelajari Rangkaian Konverter Daya. Jurnal Teknologi Informasi \& Pendidikan, 6(2), 2.

Atmam, Tanjung, A., \& Zulfahri. (2018). Analisis Penggunaan Energi Listrik Motor Induksi

Tiga Phasa Menggunakan Variable Speed Drive (VSD). SainETIn, (pp. 52).

Chapman, S. J. (1991). Electric Manchinery Fundamental (Second edition). United States: McGraw-Hill.

Desphande, M. V. (1990). Electric Motor Applications and Control. India: Wheller.

Fizgerald, A. K. (1909). Electric Machinery Fifth Edition in SI units. London: McGraw-Hill.

Hariyanto, N., Saodah, S., \& Robby, A. (2016). Analisis Karakteristik Kerja Motor Listrik Hoist di PT. Nikkatsu Electric Works. SENTIA, 86.

Haryanto, H. (2011). Pembuatan Modul Inverter sebagai Kendali Kecepatan Putaran Motor Induksi. Rekayasa, 4(1), 9-20.

Hushaini, M., \& Hasan, H. (2019). Stabilisasi Tegangan DC Menggunakan Boost Konverter. Seminar Nasional dan Expo Teknik Elektro (p. 128). Aceh: Jurusan Teknik Elektro dan Komputer, Universitas Syiah Kuala.

Indonesia, P. D. (2016). Buku Pedoman Pemeliharaan Mesin CNC. Bandung: PT. Dirgantara Indonesia (Persero).

Juarsah, M. A., Facta, M., \& Nugroho, A. (2015). Perancangan DC Chopper Buck-Boost Converter Penguatan Umpan Balik IC TL 494. Transient, 4(3), 597. 
Jufrizaldy, M., Ilyas, \& Marzuki. (2020). Rancang Bangun Mesin CNC Milling menggunakan System Kontrol GRBL untuk Pembuatan Layout PCB. Jurnal Mesin Sains Terapan 4(1), 37.

Nurlana, M. E., \& Murnomo, A. (2019). Pembuatan Power Supply dengan Tegangan Keluaran Variabel Menggunakan Keypad Berbasis Arduino Uno. Edu Elektrika, 72.

Permana, F. Y., \& Rameli, M. (2013). Pengaturan Kecepatan Spindle pada Retrofit Mesin Bubut CNC Menggunakan Kontroler PI Gain Scheduling. Jurnal Teknik Pomits, 1-5.

Powersim. (2020). PSIM User's Manual, Version 9.1. Powersim Inc.

Wibowo, B. A., \& Facta, M. (2013). Simulasi Kinerja Inverter - Rectifier Kelas D - E Berbasis PSIM. Transient, 2(4). 2. 